Florida International University FIU Digital Commons

FIU Electronic Theses and Dissertations

University Graduate School

6-25-1998

\title{
Critical problem solving scale : creating and choosing alternative solutions
}

Janene R. Bussell

Florida International University

DOI: $10.25148 /$ etd.FI14052501

Follow this and additional works at: https://digitalcommons.fiu.edu/etd

Part of the Cognition and Perception Commons

\section{Recommended Citation}

Bussell, Janene R., "Critical problem solving scale : creating and choosing alternative solutions" (1998). FIU Electronic Theses and Dissertations. 1997.

https://digitalcommons.fiu.edu/etd/1997

This work is brought to you for free and open access by the University Graduate School at FIU Digital Commons. It has been accepted for inclusion in FIU Electronic Theses and Dissertations by an authorized administrator of FIU Digital Commons. For more information, please contact dcc@fiu.edu. 
FLORIDA INTERNATIONAL UNIVERSITY

Miami, Florida

CRITICAL PROBLEM SOLVING SCALE:

CREATING AND CHOOSING ALTERNATIVE SOLUTIONS

A thesis submitted in partial fulfillment of the

requirements for the degree of

MASTER OF SCIENCE

in

PSYCHOLOGY

by

Janene R. Bussell

1998 
To: Dean Arthur W. Herriott

College of Arts and Sciences

This thesis, written by Janene R. Bussell and entitled Critical Problem Solving Scale: Creating and Choosing Alternative Solutions, having been approved in respect to style and intellectual content, is referred to you for judgement.

We have read this thesis and recommend that it be approved.

Scótt L. Fraser

C. Viswesvaran

William M. Kurtines, Major Professor

Date of Defense: June 25, 1998

The thesis of Janene R. Bussell is approved.

Dean Arthur W. Herriott

College of Arts and Sciences

Dean Richard L. Campbell

Division of Graduate Studies

Florida International University, 1998 


\author{
ABSTRACT OF THE THESIS \\ CRITICAL PROBLEM SOLVING SCALE: \\ CREATING AND CHOOSING ALTERNATIVE SOLUTIONS \\ by \\ Janene R. Bussell \\ Florida International University, 1998 \\ Miami, Florida \\ Professor William M. Kurtines, Major Professor
}

This thesis extends previous research on critical decision making and problem-solving by refining and validating a self-report measure designed to assess the use of critical decision making and problem solving in making life choices. The analysis was conducted by performing two studies, and therefore collecting two sets of data on the psychometric properties of the measure. Psychometric analyses included: item analysis, internal consistency reliability, interrater reliability, and an exploratory factor analysis. This study also included regression analysis with the Wonderlic, an established measure of general intelligence, to provide preliminary evidence for the construct validity of the measure. 
I. INTRODUCTION

II. LITERATURE REVIEW

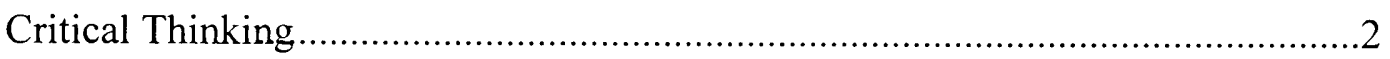

Critical Thinking in Problem Solving.............................................................. 5

The Development of the Critical Problem Solving Scale(CPSS.)......................... 7

Critical Decision Making and Problem Solving in Moral Dilemmas......................7

Interpersonal Problem Solving...............................................................................

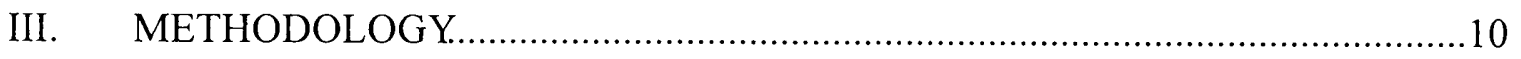

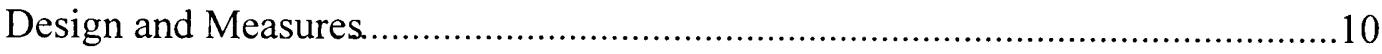

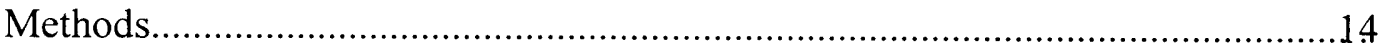

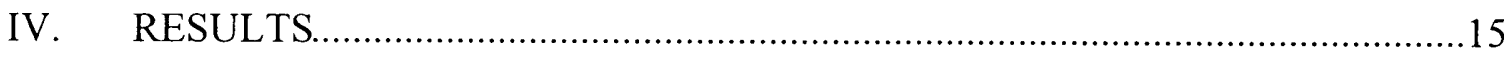

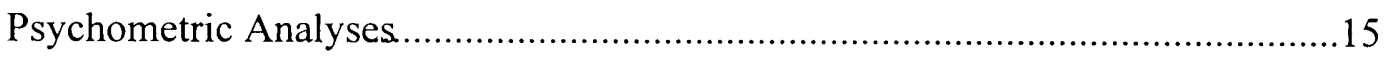

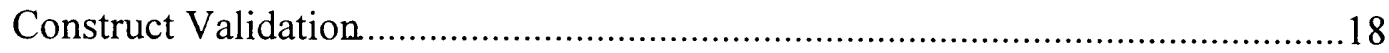

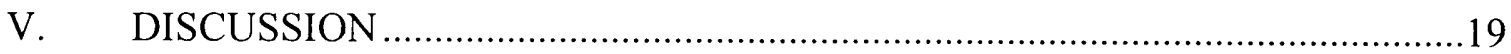

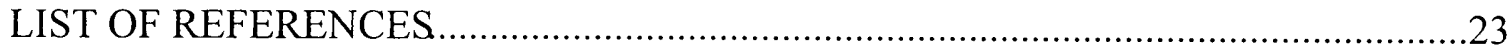

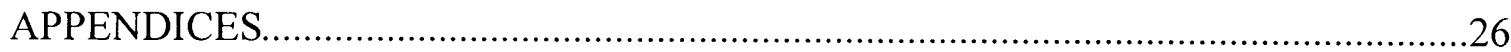




\section{LIST OF TABLES}

TABLE

PAGE

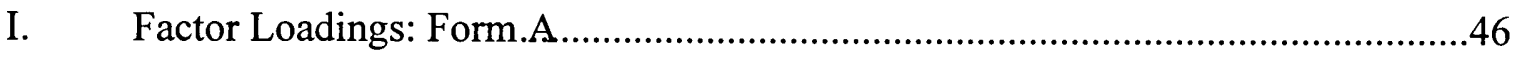

II. Means and Standard Deviations: Form A A........................................................47

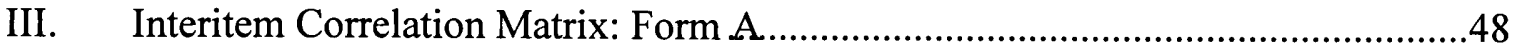

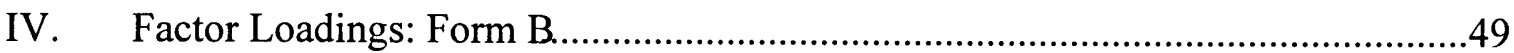

V. Means and Standard Deviations: Form.B.....................................................50

VI. Interitem Correlation Matrix: Form B........................................................5 


\section{Introduction}

The framework for the project described in this paper was derived from an ongoing program of psychosocial theory and research (Berman, Ittel, Williamson, \& Kurtines, 1995; Kurtines, 1984; 1987; 1990; Kurtines, Mayock, Pollard, Lanza and Carlo, 1991; Pollard, Kurtines, Carlo, Dancs, and Mayock, 1991). This psychosocial theoretical approach is in some respects similar to other psychosocial theories proposed by theorists such as Fromm (1947), Lewin (1935), Sullivan (1953) and more recently Erikson (1965). Our work, however, differs from these other psychosocial theories in that it derives from a co-constructivist perspective on human behavior and development (Kurtines, 1993). This perspective views human beings as a self-directed, goal-oriented bio-psychosocial organisms with complex, higher order cognitive and communicative capacities that enable them to engage in decision making and problem solving activities that affect the quality of their lives.

The measure that was refined and validated for this project was thus developed within a perspective that provides a framework for conceptualizing the role that criticaldecision making and problem solving plays in making life choices. This framework conceptualizes critical decision making and problem solving as involving specific types or categories of operations and actions that human beings use in making individual life choices. Critical decision making and problem solving is conceptualized as involving complex, higher order types of operations and actions that occur relatively infrequently in ordinary decision making and problem solving. However, although they occur infrequently, they are important in human decision making and problem solving because 
of the role they play when ordinary decision making and problem solving activities fail. They are an important part of human decision making and problem solving because of the role that they play in resolving difficulties that go beyond the range of ordinary decision making and problem solving activities. Critical thinking and decision making thus involves specific types of decision making and problem solving operations and actions that can be most usefully conceptualized within a broader framework that includes an account of the full range of operations and actions that play a role in decision making life choices.

\section{Critical Thinking}

Much of the work on critical thinking has been on the development and use of logical reasoning skills in problem solving and decision making (Glaser, 1984). However, a number of concerns have been raised about the degree to which logical reasoning skills encompass the full range of skills involved in critical thinking. Brabeck and Wood (1985), for example, have pointed out that logical reasoning skills are particularly useful in solving "well-structured" problems. Well-structured problems are characterized by having known problem characteristic properties that lead to single Verifiable and certain answers. Many "real-world" problems, however, are complex or "ill-structured" problems (Churchman, 1971) for which there is often "conflicting or incomplete information," have unknown, unspecifiable or even conflicting problem characteristics and lead to more than one of a number of solutions that are neither certain nor verifiable. Such problems often involve the use of more than logical reasoning skills; they involve other types of higher order reasoning processes. Kitchener and King (1981), for example, have proposed that "reflective judgment" is also an important higher order 
type of cognitive skill. Reflective judgements are not concerned with logical problem solving skills; rather, reflective judgements concern the nature of the epistemological and metaphysical assumptions that affect the ways people use evidence and justify beliefs.

The conceptualization of critical thinking in problem solving and decision making used in this project draws on the consensus that has begun to emerge in the literature with respect to the general features of a broader, more practical conception of critical thinking. First, critical thinking is generally recognized as a "higher order" cognitive capacity and thus similar to other types of higher order cognitive abilities (Glasser, 1984). Critical thinking, for example, includes the capability of monitoring and evaluating one's own performances, i.e., thinking about thinking (Greeno, 1989), and is thus a type of metacognition (Bransford, et al. 1986). Critical thinking, however, involves more than metacognitive processes. Critical thinking is a complex, higher order type of cognitive process that facilitates problem solving activities in contexts of disequilibrium. That is, critical thinking is a higher order type cognitive process that facilitates generating adaptive responses under changing conditions. This section outlines the conceptualization of critical thinking that was used in this project. It begins by describing the type of activities normally involved in human goal oriented behavior. It then describes the types of activities involved in solving problems that arise with respect to human goal oriented behavior. This description provides the framework for outlining a conceptualization of the role that critical thinking plays in these problem solving activities.

As a self-directed, goal-oriented bio-psychosocial organism, the human species, like other species, is confronted with the task of maintaining an equilibrium with its 
environment. Under conditions of equilibrium, human goal oriented behavior is oriented toward goals actually or potentially attainable under existing conditions and toward maintaining the equilibrium necessary for achieving those goals. Goal-oriented behavior involves both means and ends. Ends refers to goals, aims, outcomes, etc. and means refers to the plans, procedures, methods, strategies, etc. by which goals, aims, or outcomes are achieved or accomplished. Problems arise with respect to human goaloriented behavior when changing organismic and/or environmental conditions create a disequilibrium that disturbs, interrupts, or disrupts goal oriented behavior. Because goaloriented behavior involves both means and ends, problems can arise with respect to either means or ends or both. The disequilibrium created by changing conditions results in two basic types of problems with respect to human goal oriented behavior: instrumental and normative. A problem is instrumental when it involves the means or method by which goals or ends are (or can be) achieved. A problem is normative when it involves the (goodness, rightness, usefulness, etc.) of the goals or ends themselves. Thus, changing conditions create a disequilibrium that challenges the utility of means or methods and/or the validity of goals or ends and disturbs, interrupts, or disrupts goal oriented behavior. Successful problem solving involves establishing or re-establishing an equilibrium that restores successful goal oriented behavior. The three basic types of activities involved in successful problem solving are briefly described next.

First, successful problem solving involves recognizing when a problem exists. Recognizing when a problem exists includes not only recognizing that goal oriented behavior has been disturbed, interrupted, or disrupted, but also identifying and rendering explicit the nature of the problem. This includes identifying whether the problem is 
instrumental, normative, or both and identifying and rendering explicit the problematic means or methods and/or goals or ends. Successful problem solving, however, requires more than recognizing that a problem exists and what the problem is. Successful problem solving also involves generating potential alternatives (instrumental or normative) for resolving the problem and restoring equilibrium. If the problem is instrumental, generating alternatives involves either transforming or reconstructing and/or inventing or creating new or novel means or methods for achieving goals and ends. If the problem is normative, generating alternatives involves either transforming or reconstructing and/or inventing or creating new or novel goals and ends themselves. Finally, successful problem solving also involves evaluating, selecting, and implementing the most adaptive alternatives from among the competing means or methods and/or goals or ends. Successful problem solving thus involves three basic activities: 1) recognizing when a problem exists and identifying what the problem is, 2) generating alternatives for solving the problem, and 3) selecting the most adaptive alternative.

\section{Critical Thinking in Problem Solving}

Now that we have outlined the types of activities involved in successful problem solving, we can turn to the role that critical thinking plays in these activities. Our view of the role that critical thinking has to play in problem solving activities, draws on the consensus which has emerged in the literature with respect to a more practical conception of critical thinking. As it applies to individual problem solving, critical thinking involves two basic processes: suspension of judgment and critical evaluation. These two processes have an important role to play in all three types of problem solving activities. Suspension of judgment involves treating the problem hypothetically and entertaining the 
possible utility and/or validity of all potential interpretations with respect to identifying the problem, the alternatives, and the best solution. Critical evaluation involves challenging, questioning, and subjecting to critical examination potential interpretations as to identifying the problem, the alternatives, and the best solution. Critical thinking is thus thinking that involves adopting a "critical" (i.e., skeptical or questioning) stance with respect to the problem to be solved, including all activities related to successfully solving the problem.

The use of critical thinking in problem solving has an important role to play in successfully solving problems that arise with respect to human goal oriented behavior because it facilitates the resolution of challenges to the utility or validity of the goaloriented behavior. With the development of the capacity for critical thinking, the individual acquires the capacity for a type of problem solving that is unique to the human species. The capacity for critical thought enables human beings to do more than solve problems that arise with respect to goal oriented behavior. The capacity for critical thought enables human beings to challenge or question the utility of the means or methods by which goals are achieved and to transform or reconstruct them and/or to invent or create new ones when necessary. More importantly, the capacity for critical thought enables human beings to challenge or question the value or validity of goals or ends themselves and to transform or reconstruct them and/or to invent or create new ones when necessary. The development of the capacity for critical thought thus not only enables the individual to engage in complex forms of problem solving, but it is also one of the complex, higher order capacities that enables human beings to transform or reconstruct and/or to invent or create the goals and values that shape and influence the 
direction of personal change.

\section{Background and Significance}

The Development of the Critical Problem Solving Scale (CPSS)

The Critical Problem Solving Scale draws on two lines of research. More specifically, it draws on our previous research on developing interview measures of critical decision making and problem solving in moral dilemmas for the test stimuli and the scoring procedure for the CPSS, and on the literature on interpersonal problem solving for the format for generating alternatives used for the CPSS.

Critical Decision Making and Problem Solving in Moral Dilemmas

The first line of research that the CPSS draws on is previous research conducted at the Psychosocial Development Lab on critical decision making and problem solving in moral dilemmas. This work involved two studies. The first study by Williamson (1992) focused on the development of an interview measure of Critical Cognitive Style in moral decision making and problems solving. The second study by Arrufat (1995) focused on the development of a refinement of this interview measure, called the Critical Decision Making and Problem Solving Scale (CDP-MD). Williamson (1992) reported the development and refinement of an interview measure of critical cognitive style designed to assess critical thinking in sociomoral dilemmas. The subjects for the study consisted of 72 young adult college students. Williamson described the development of the administrative format, test stimuli, administration procedure, and the coding/scoring procedures for the interview measure of critical cognitive style that provided the basis for the critical thinking part of the CDP-MD. Arrufat (1995) reported the development and refinement of the interview measure developed as part of the Williamson study, called the 
Critical Decision Making and Problem Solving Scale (CDP-MD). The subjects for the study consisted of 24 young adult college students. Arrufat (1995) described the development of refinements for the test stimuli and the coding/scoring procedures for the CDP-MD that will be adapted for use the with the CPSS.

Interpersonal Problem Solving

The second line of research that the CPSS draws on is the large literature on interpersonal problem solving. Although most of the work that has been done in this literature involved developing interventions with young children, the format that has evolved for generating alternatives is readily adapted for use with other age populations. The specific work that we draw on is that of Spivack and Shure (1982). In their work, they have found that maladaptive perceptions of interpersonal situations interfere with young children's ability to successfully cope with several types of social situations. This inability to successfully cope with these situations is hypothesized to relate to acting out behaviors in children. Spivack and Shure have conducted an extensive program of research that focuses on a cognitive approach to solving real life problems (1982). A main focus of their work is on the construct of interpersonal problem solving capacity. Spivack and Shure's (1982) focus is on fostering in children the ability to generate alternatives to problematic interpersonal situations. Spivack (1976) has stated the following:

"if individuals can be helped to develop a cognitive problem solving style for real-life problems and to generate their own ways of solving the typical interpersonal problems that arise during their day, they will be able to cope better than before and will manifest this improvement in changes in overt 
behavioral adjustment." (pg. 54)

Thus, under this rationale the failure to think about the possible alternatives available under any given set of circumstances relates to a maladaptive perception in children. This maladaptive perception is characterized by the limited realization of the options available in a given situation. Furthermore, the lack of thought about the implications and the consequences of any given option is also a skill that is hypothesized to be under utilized by children and youths who engage in problematic behaviors (Spivack \& Shure, 1982). More specifically, those individuals who do not fully consider all of the potential solutions to a problem, and the consequences, are more likely to exhibit problem behaviors.

As part of this program of research, Spivack and Shure have provided the empirical basis for much of the research done with cognitive problem solving in childhood. In their original research, Spivack and Shure (1979) focused on aspect of problem solving which includes the generation of alternatives, more recently they have begun to focus on the process involved in finding a solution. Spivack and Shure have proposed such concepts as consequential thinking, which involves thinking about what will happen when you choose a particular solution, and perspective taking, which involves thinking about another person's feelings (1989). These concepts are close to critical thinking, but they do not fully encompass critical thinking because they do not ask the individual to suspend judgement, or try to look at the problem objectively, nor do they ask the individual to subject their alternatives to critical evaluation, or scrutiny from others and themselves. However, the basic format collecting information on the subject's capacity to generate solutions for the CPSS was adapted from this work. 


\section{The Current Study}

This study was conducted to extend the previous research in two ways: 1) to conduct psychometric analyses (reliability, factor analyses, etc.) on the CPSS and 2) to provide preliminary evidence for the construct (concurrent) validity of the CPSS.

\section{Design and Measures}

The Critical Problem Solving Scale (CPSS)

The CPSS was adapted from the measure of critical cognitive style reported by Williamson (1992) which was further refined by Arrufat (1995); Critical Decision Making and Problem Solving Scale (CDP-MD). An appropriate self-report administrative format and six pilot dilemmas were developed for the CPSS. As noted above, researchers have traditionally used a relatively open-ended interview format. The format that was developed for the CPSS is a self-administered, self-report format that uses written responses. The CPSS was thus developed to allow individuals to generate and evaluate as many alternative solutions as possible to the moral dilemmas. The CPSS presents the subject with three sociomoral dilemmas. Each dilemma is followed by a set of instructions designed to elicit responses pertaining to three different areas of critical thinking and problem solving. The first question asks the subject to generate as many alternative solutions as possible. The second question asks the subject to list the pros or cons of their alternatives. The final question asks the subjects to pick the best alternative and explain why they choose it.

The CPSS (see Appendices A \& B) consists of a nine page self-report questionnaire and a five page answer booklet that can be group administered. The questionnaire contains one introductory or background page and three additional pages 
each of which presents a different moral dilemma. More specifically, the questionnaire asks subjects to provide a list of as many alternative solutions as possible. Then the subjects are asked to evaluate the best alternative by listing all of the good and bad aspects about this alternatives. Next the subjects are asked to come up with an alternative that opposes their best choice and to state why this could be a better choice. Finally the subject is again asked to pick the best alternative and explain why it was chosen.

\section{$\underline{\text { Test Stimuli }}$}

The test stimuli for the Critical Problem Solving Scale consists of three situations involving fictional characters confronted with hypothetical moral dilemmas. The stimuli were adapted from the Moral Identity Scale (MIS; Kurtines, 1991). This scale was originally designed to assess individual, developmental, and cultural variation in value orientation. The value orientations the scale measures are a Deontological versus Teleological orientation. A deontological orientation focuses on the importance of duty or obligation in moral choices; a teleological orientation focuses on the importance of outcome or consequence in moral choice. The dilemmas from the MIS are about hypothetical characters (Hobbits). The following is an example from the MIS:

After Rob had given both Sam and Dale their presents, the three Hobbits began to prepare dinner. And it was a splendid supper indeed, for all of the hard work and fresh air had given the Hobbits a healthy appetite. Later, while sitting on the porch, Sam told Rob that he had found a magic black mushroom in the field. Black mushrooms were said to have many different types of powers. For example, it is said that one bite of a black mushroom could make Hobbits act in strange ways, sometimes even 
causing them to harm themselves. Now, while Sam had a warm and friendly disposition, he was also noted for being very impulsive and for doing foolish things. Consequently, Sam asked Rob to keep the black mushroom for him. However, before giving Rob the mushroom, Sam made Rob swear a double solemn oath, which Hobbits take very seriously, to give him the black mushroom back whenever he asked for it. Later on in the evening, in the middle of a fitful sleep, Sam woke up. He had been feeling very bad about his father, and he asked Rob to give him the black mushroom back because he wanted to eat some. Rob was not sure about what to do so he considered his choices.

\section{Scoring : The Critical Problem Solving Scale}

The CPSS yields a quantitative scores for creativity, suspension of judgment, and critical evaluation.

Creativity Score. The total Creativity Score for the CPSS consists of the simple sum of the number of different and distinct alternatives generated in response to all of the dilemmas.

Suspension. The Suspension Score for the CPSS is the sum of the number of worst choices and justifications for those choices. The worst choices were generated when the participants were asked to describe the worst choice and list reasons why this could still be a good or better alternative than their best choice across the three dilemmas. The suspension score is hypothesized to be indicative of suspension of judgement.

Self-Challenge. The Self-Challenge score is the sum of the number of cons generated (i.e., the number of negative aspects of the best alternative) across the three 
dilemmas. A balance between self-challenge scores and scores representative of suspension of judgement (i.e., modification and suspension scores) are hypothesized to be indicative pf critical thinking and problem solving.

Modification. The modification score is the sum of the number of modifications given across all three dilemmas. During the measure, the participants were asked to choose the best alternative, to choose the worst alternative, and to then again choose a best alternative. A modification was recorded if the participant changed their best choice on the final prompt when compared to the first. Modifications were coded on a scale ranging from 0-2 points. One point was given if the participant modified and did not give a justification, two points were given if the participant modified and gave a justification and a score of zero was given if the participant did not modify. It is assumed that the modification was caused by the participants having to justify a position to counter their best choice. When the participant modified their original choice, it is hypothesized that they engaged in critical decision making and problem solving. The participant had to suspend judgement and entertain the potential validity of an opposing point of view. $\underline{\text { Wonderlic }}$

The Wonderlic (Wonderlic, 1984). has been used for a number of years as a measure of academic intelligence for industrial use. The Wonderlic is a 50-item 12 minute test that can also be group administered. It yields a single score composed of verbal, numerical and spatial content areas. Extensive norms have been established on an assorted number of occupational groups. It is reported that parallel form and test-retest reliabilities range from .70 to .90 . (Anastasi, 1988).

Psychometric Analyses 
The psychometric analyses conducted on the CPSS included factor analyses, item analyses, internal consistency reliability and interrater reliability.

\section{$\underline{\text { Construct Validation }}$}

Construct validity concerns the degree to which a test may be shown to measure a theoretical construct or trait (Anastasi, 1988). In discussing the concept of constructvalidation, Anastasi has pointed out that various categories of evidence can be used to support the construct validity of a scale, including such types as developmental change, correlations with other tests (concurrent validity), and convergent and discriminant evidence. The validational component of this study is concerned with providing evidence for the concurrent validity of the CPSS. More specifically, this study examines the relationship between critical thinking (and its components) as measured by the CPSS and the type of logical problem solving skills assessed by a measure of general intelligence such as the Wonderlic (Wonderlic, 1984).

\section{Methods}

\section{$\underline{\text { Participants }}$}

The participants for the psychometric study consisted of 138 undergraduate psychology students at Florida International University (50 males and 88 females). The sample was split in half and 69 of the participants completed Form A and 69 completed Form B of the CPSS. Preliminary analysis across variables yielded no significant gender differences.

Procedure

All participants were recruited in class. Individuals who agreed to participate were initially given the Wonderlic, then they were given the CPSS questionnaire to be 
completed during class time.

\section{Results}

\section{Psychometric Analyses}

\section{$\underline{\text { Form A }}$}

Factor Analysis. This section describes the initial factor analysis of the CPSS. For this analysis, the 12 items from the four subscales (Creativity, Suspension, SelfChallenge, and Modification) were subjected to a Alpha Factoring Solution (SPSS, analysis with an oblique rotation). The Alpha solution of the 12 items yielded three factors with an eigenvalue greater than 1.0. The first factor which accounted for the largest proportion of variance, was a relatively large factor defined as a creativity/challenges with all of the creativity and challenge items loading on this factor. This factor accounted for 26.1 percent of the total variance $(\mathbf{e}=3.14)$. Factors 2 and 3 ( $\mathbf{e}$ $=1.50 \& 1.03$ ) were more moderate in size and accounted for approximately the same proportion of variance, $12.5 \%$ and $8 \%$. Factor 2 was defined as a modification factor with all three items loading on this factor from the modification scale. Factor 3, the factor that accounted for the least variance, was a suspension of judgment factor, but not so clearly defined with only two suspension of judgement items loading on this factor. A fourth factor $(\mathbf{e}=.60)$ appeared to be inversly related to the other three factors and only accounted for $5.03 \%$ of the variance. Table 1 presents the loadings from the factor structure matrix.

Item Analysis. An item analysis was conducted on each of the scales within the CPSS that included item total correlations, squared multiple correlations, scale alphas 
with the items deleted, scale means with the item deleted, and scale variance with the item deleted (cf. Noruis/SPSS, 1988). The results indicated that none of the alpha coefficients for any of the scales would be significantly increased by removing any of the items.

Table 2 reports the means and standard deviations for Form A. Table 3 reports the interitem correlation matrix for 12 items for Form A (four subscales with three items each). As can be seen from the Table3, the subscales displayed a relatively high degree of interitem correlation, with [highest] the expception of the Suspension of Judgment Scale. More specifically, participant Suspension of Judment responses to Dilemma 3 were inconsistent with their response to Dilemma 1 and 2 for this subscale.

Internal Consistency Reliability. Internal consistency reliability was estimated for the each of the scales within the CPSS (Creativity, Suspension, Challenge, and Modification) using the Alpha coefficient. The Alpha coefficient for the creativity scale was .75 , for the challenge scale was .69 , for suspension of judgement was .50 and for modification was 68 .

Interrater Reliability. Responses to the CPSS were coded by three raters trained in using the CPSS scoring protocol. Interrater reliability for the scoring protocol displayed $89 \%$ agreement. The same team of raters was used in both administrations (Form A and Form B) for scoring of the CPSS.

\section{$\underline{\text { Form B }}$}

Factor Analysis. This section describes the secondary factor analysis of the CPSS. For this analysis, the 12 items from the four subscales (Creativity, Suspension, Self-Challenge, and Modification) were subjected to a Alpha Factoring Solution (SPSS, 
analysis with an olbique rotation). The Alpha solution of the 12 items yielded three factors with an eigenvalue greater than 1.0. Again, the first factor, accounting for the largest proportion of variance, was a relatively large factor, defined as creativity/challenges with all but one of the creativity and challenge items loading on this factor (see Table 4). However, in this analysis, in addition to the creativity and challenge items, the suspension of judgement items also loaded on this first factor. This factor accounted for 27.9 percent of the total variance $(\mathbf{e}=3.35)$. Factor 2 was more moderate $(\mathbf{e}=1.22)$ and accounted for $10.2 \%$ of the variance. Again, this factor was defined as a modification factor with all three items loading on this factor from the modification scale. Factor $3(\mathbf{e}=1.02)$ was smallest in size and accounted for the least amount of the variance, $7.9 \%$. This third factor was less clearly defined than in the initial analysis with only one item (the creativity score from dilemma number 2 ) clearly loading on this factor. Finally, a fourth factor $(\mathbf{e}=.70)$ appeared to be inversely related to the other three factors and only accounted for $5.82 \%$ of the variance. Table 4 presents the loadings from the factor structure matrix.

Item Analysis. An item analysis was conducted on each of the scales within the CPSS that included item total correlations, squared multiple correlations, scale alphas with the items deleted, scale means with the item deleted, and scale variance with the item deleted (cf. Noruis/SPSS, 1988). The results indicated that none of the alpha coefficients for any of the scales would be significantly increased by removing any of the items.

Table 5 reports the means and standard deviations for Form B. Table 6 reports the interitem correlation matrix for 12 items for Form B (four subscales with three items 
each). As can be seen from Table 6 , the subscales displayed a relatively high degree of interitem correlation, with [highest] the exception of the Suspension of Judgment Scale. More specifically, participant Suspension of Judgment responses to Dilemma 3 were inconsistent with their response to Dilemma 1 and 2 for this subscale.

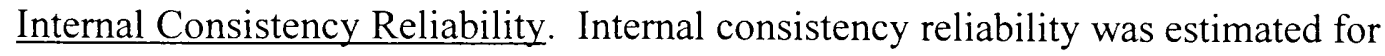
the each of the scales within the CPSS (Creativity, Suspension, Challenge, and Modification) using the Alpha coefficient. The Alpha coefficient for the creativity scale was .62., for the challenge scale was .54 , for suspension of judgement was .63 and for modification was .71

Construct Validation

Construct validity for the CPSS was evaluated by using correlations with another test to estimate concurrent validity. More specifically, regression analytic techniques were used to estimate the relationship between the four components of critical thinking as measured by the CPSS and the type of logical problem solving skills assessed by the Wonderlic.

Total Sample (Form A + Form B)

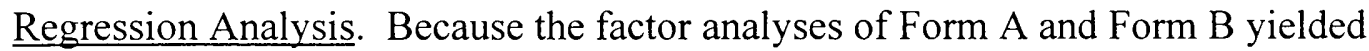
a similar factor structure, the first construct validational analyses consisted of using regression analytic techniques to calculate the correlation of the Wonderlic with each of the four subscales of the CPSS for the total sample. The Wonderlic was used as the dependent variable while the four subscales constituted the multiple independent variables. The result was a significant equation [adjusted $\underline{\mathrm{R}}^{2}=.075, \underline{\mathrm{F}}(4,133)=3.79, \underline{\mathrm{p}}$ $<.006]$. The beta weights for the equation indicated that the suspension of judgement ( $\underline{B}$ 
$=.21, \mathrm{t}=2.29, \underline{\mathrm{p}}<.023)$ and the creativity subscale $(\underline{\mathrm{B}}=.20, \mathrm{t}=1.89, \underline{\mathrm{p}}<.06)$ were both significant predictors of the Wonderlic score. In order to examine possible differences on the predictors between forms, further regression analyses were conducted separately by form (A and $\mathrm{B})$.

\section{$\underline{\text { Form A }}$}

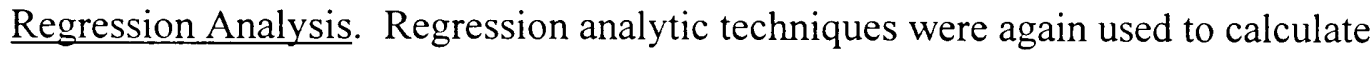
the correlation of the Wonderlic with each of the four subscales on Form A of the CPSS. The Wonderlic was used as the dependent variable while the four subscales constituted the multiple independent variables. This time the result was a significant equation [adjusted $\left.\underline{\mathrm{R}}^{2}=.097, \underline{\mathrm{F}}(4,64)=2.82, \underline{\mathrm{p}}<.05\right]$ ]. There was also a different result in that the beta weights for the equation indicated that only the suspension of judgment subscale was a significant predictor of the Wonderlic score $(\underline{B}=.33, \underline{t}=2.41, \underline{p}<.019)$.

\section{$\underline{\text { Form B }}$}

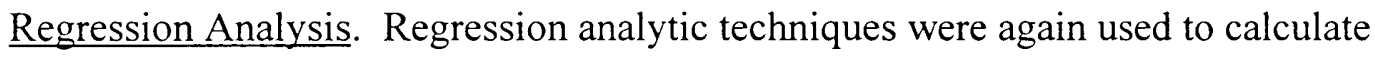
the relationship of the Wonderlic with each of the four subscales on Form B of the CPSS. The Wonderlic was used as the dependent variable while the four subscales constituted the multiple independent variables. This time the result was a nearly significant equation [adjusted $\underline{\mathrm{R}}^{2}=.07, \underline{\mathrm{F}}(4,64)=2.37, \underline{\mathrm{p}}<062$ ]. The beta weights for the equation indicated that only the creativity subscale was a significant predictor of the Wonderlic score $(\underline{B}=.37, \mathrm{t}=2.40, \underline{\mathrm{p}}<.019)$.

\section{Discussion and Summary}

The research conducted as part of this study extended and refined our capacity to measure the use of critical thinking and problem solving in several ways. The research 
accomplished this goal by extending the work that has been done on the development of measures of critical thinking and problem solving. More specifically, a self-report measure, the CPSS, that combines measures of critical thinking and problem solving developed in previous research has been tested.

The results of the psychometric analyses indicated that both forms of the measure have adequate psychometric properties. First, the factor analyses indicated that both forms had a similar factor structure, but not falling out clearly along four dimensions that parallel the four subscales. Rather, the results consistently supported a three factor solution, with the first and largest factor being one defined as a challenge/creativity factor, with challenge items consistently loading of the first factor for both Form A and B, but not creativity. The second factors were also similar in both forms, being defined as a modification factor. Finally, the third and smallest factor was not clearly defined for either form, with suspension of judgment forming the third factor for Form A and forming part of the first factor for Form B. Creativity, in contrast, clearly fell out on the first factor for Form A, but was spread out across all three factors for Form B. This may reflect the fact that the cognitive operations associated with critical thinking are made up of fewer orthogonal processes than originally hypothesized. More specifically, that processes associated with challenges, creativity, and suspension of judgment are more highly interrelated with each other than with the process of modification.

Second, the results of the item analyses and reliability analyses indicated that the measure exhibited adequate reliability. More specifically, the item analyses indicated that all of the items contributed to meaningful score variance. The internal consistency reliability estimates further indicated that the subscales of the CPSS were reasonably 
coherent, with Alphas ranging from .50 to .75 for Form A and .54 to .71 for Form B. Finally, the coding procedure proved to be highly reliable, with interrater agreement reaching $89 \%$.

Finally, the regression analyses investigating the relationship of the CPSS subscales to a measure of general intelligence provided support for the divergent validity of the CPSS. The results indicated, for the total sample (across both forms), that the subscales of the CPSS most related to the use of logical reasoning were creativity and suspension of judgement. Moreover, the Betas for both were positively and significantly predictive of the total scores on the Wonderlic. However, the overall magnitude of the Betas was small, as was the total R2, indicating that the overlap between the measures was relatively small. The results suggests that critical thinking does have a logical reasoning component, but that it also taps other divergent cognitive processes such as generating alternatives.

To further examine possible differences between forms, regression analyses were conducted separately by form ( $\mathrm{A}$ and $\mathrm{B})$. The results indicated that the different forms tapped different dimensions, with creativity being more relevant for Form $\mathrm{A}$ and suspension of judgement being more relevant to Form B.

Although the findings from this study sheds some light on the process of critical thinking, the research has several areas of limitations. For example, this study used a measures of general intelligence but did not include any measures of personality (e.g.: the NEO-PI). However, it is possible that personalty factors, in addition to intelligence, also play a role in critical thinking. Future research consequently, might be directed toward addressing the issue of the role personality factors. 
Another possible limitation might be that in addition to the role of personality, the role of development was also not addressed in this study. For example the participants in this study were undergraduate university students, thus making them a homogenous group with regard to age. It is possible that the cognitive processes involved in critical thinking and problem solving activities may occur differently at different age levels.

Finally, future research might be directed toward investigating the role of noncognitive talents and abilities in critical thinking and problem solving activities. For example, research drawing upon Waterman's $(1990,1992)$ concepts of personal expressiveness and identity exploration might indicate that affective processes may also play a role in critical thinking. Future research might also extend the work done here by addressing the issue of the affective processes and their role in fostering the development of critical thinking and problem solving skills. 


\section{References}

Anastasi, A. (1988). Psychological testing (6th ed.). New York: Macmillan.

Brabeck, M. M., \& Wood, P. K. (1985). Cross-sectional and longitudinal evidence for differences between well-structured and ill-structured problem-solving abilities. In M. L. Commons, C. Armon, L. Kohlberg, F. Richards, T. A. Grotzer, \& J. D. Sinnott (Eds), Adult development: Models and methods in the study of adolescent and adult thought. New York: Praeger.

Bransford, J., Sherwood, R., Vye, N., Rieser, J. (1986). Teaching Thinking and Problem-solving. American Psychologist , 41, 1078-1089.

Churchman, C. W. (1971). The design of inquiring systems: Basic concepts of systems and organizations. New York: Basic Books.

Erikson, E. H. (1964). Insight and responsibility. New York: Norton

Fromm, E. (1947). Man for Himself. New York, Rinehart.

Glaser, R. (1984). Education and thinking: The role of knowledge. American Psychologist, 39, 93-104.

Greeno, J. G. (1989). A perspective on thinking. American Psychologist, 44, 134-141.

Kitchener, K., \& King, P. (1981). Reflective judgement: Concepts of justification and their relationship to education. Journal of Applied Developmental Psychology , 2, 89-116.

Kurtines, W. (1982). Moral behavior as rule governed behavior: A psychosocial role theoretical approach to moral decision making. Symposium presentation: Integrative new approaches to moral behavior and development, American Psychological Association's Annual Convention, Washington, D.C. 
Kurtines, W. (1984). Moral behavior as rule governed behavior: A psychosocial role theoretical approach to moral behavior and development. In W. Kurtines \& J. L. Gewirtz (Eds.), Morality, moral behavior, and moral development. New York: John Wiley \& Sons, 303-324.

Kurtines, W. (1986). Person and situation effects on moral decision making: A psychosocial role theoretical approach. Journal of Personality and Social Psychology, 50, 784-791.

Kurtines, W. (1987). Psychosocial theory as a nomotic science. In W. Kurtines \& J. L. Gewirtz (Eds.), Moral development through social interaction. New York: John Wiley \& Sons.

Kurtines, W. (1990). Psychosocial development: A co-constructivist perspective. Unpublished manuscript, Florida International University, Miami, Florida.

Kurtines, W. (1991). The Moral Identity Scale; Manual. Unpublished manuscript, Florida International University, Miami, Florida.

Kurtines, W. \& Gewirtz, J. L. (1984). Certainty and morality: Objectivistic versus relativistic approaches. In W. Kurtines \& J. L. Gewirtz (Eds.), Morality, moral behavior, and moral development. New York: John wiley \& Sons, 3-22.

Kurtines, W. \& Gewirtz, J. L. (1987). (Eds.) Moral development through social interaction. New York: John Wiley \& Sons.

Kurtines, W., Ittel, A., Williamson, S., Pollard, S. (in press). Sociomoral development from a psychosocial role theory perspective. New York: McGraw-Hill.

Kurtines, W., Mayock, E., Pollard, S. R., Lanza, T., \& Carlo, G. (1991). Social and moral development from the perspective of psychosocial theory. In Kurtines, W. \& Gewirtz, J. G. (Eds.) Handbook of moral behavior and development: Theory, research. and application (Vol. 1). New York: Erlbaum \& Associates.

Lewin, K. (1935). A dynamic theory of personality. New York: McGraw Hill. 
Norusis, M./SPSS INC. (1988). SPSS/PC+V2.0 Base Manual. Chicago: SPSS, INC.

Pollard, S. R., Kurtines, W., Carlo, G., Dancs, M., \& Mayock, E. (1991). Moral education from the perspective of psychosocial theory. In Kurtines, W., \& Gewirtz, J. L. (Eds.), Handbook of Moral Behavior and Development (Vol. 3). New York: Erlbaum \& Associates.

Sullivan, H. S. (1953). The interpersonal theory of psychiatry. New York: Norton.

Waterman, A. S. (1990). Personal expressiveness: Philosophical and psychological foundations. Journal of Mind and behavior, 11, 47-74.

Waterman, A. S. (1992). Identity as an aspect of optimal psychological functioning. In G. R. Adams, T. P. Gullotta, \& R. Montemayor (Eds.), Adolescent identity formation: Advances in adolscent development (pp.50-72). Newbury Park, CA: Sage.

Williamson, S. (1992). The Development and Validation of a Measure of Critical-Cognitive Style. Unpublished Masters Thesis, Florida International University, Miami, Florida.

Wonderlic, E. F. (1984) The Wonderlic Personnel Test. Illinois: E.F. Wonderlic Personnel Test, Inc. 
APPENDIX A

THE CPSS QUESTIONNAIRE: FORM A AND FORM B 
Directions: Answer the questions on the answer sheet.

Introduction: The following pages tell of the adventures of Rob, Sam and Dale. Rob, Sam and Dale are Hobbits. Hobbits, as you may know, live in Middle-earth. Because some of you may not be familiar with these remarkable people (and those of you who are may be uncertain about many details), we can begin with a few notes about their habits and lives before we start our tale of the adventures of Rob, Sam and Dale. For those of you who find Hobbits interesting and wish to pursue the matter further the best source of information about Hobbits (and the source from which these notes are taken) is J. R. R. Tolkien's The Lord of the Rings.

Hobbits are modest but very ancient people, shy of the "Big Folk," as they call us. They are inclined to be fat and about the same height as Dwarves. Their faces are as a rule good-natured rather than beautiful, broad, bright-eyed, and red cheeked. They are merry and hospitable folk; delight in parties, and in presents, which they give away freely and eagerly accept.

Our knowledge of the history and customs of Hobbits is extensive (and Hobbitlore makes fascinating reading), but these few remarks will serve well enough to set the stage for the adventures of the aforementioned Hobbits--Rob, Sam and Dale. As far as Hobbits go, these three are for the most part representative of their kind. All three are about the same age, though Hobbits tend to live very long and it is hard to tell just exactly what their ages are. The Hobbits' sense of morality is of interest to us because, though it is not widely known, these remarkable people do not differ at all from "Big Folk" in their moral character and conduct. Because it is easy to identify with Hobbits they provide an ideal context for studying how people make choices. The purpose of this questionnaire is to find out how you think about and make choices, and the Hobbits will serve to provide the background for raising these issues. For the next several pages we will be concerned with how Rob, Sam and Dale conduct themselves in various "moral dilemmas." The stories are obviously hypothetical but the situations are intended to represent the type of circumstances people actually frequently find themselves in. Equally obvious, as you will see, there are many different ways to respond to these dilemmas. So try to identify with the situations and answer the questions the way you honestly believe.

Begin by reading the first dilemma. When you are finished reading the first dilemma, answer the questions as indicated.

CPSS.95

Revised: $5 / 95$

Printed: 9/95 


\section{DILEMMAS}

\section{You broke it you bought it.}

Work on the farm continued. There was much to be done and the Hobbits worked with great enthusiasm. In fact, Dale and Sam even went so far as to go into town to borrow a plow from The Merchant in order to speed up clearing the field. While they were plowing together in the field, Sam began talking to Dale about the trip he had taken to a far away land, in spite of Dale's protests that he should pay more attention to their task. Suddenly, the plow struck a huge boulder and the blade broke. The plow was ruined. The Hobbits took it back to The Merchant and The Merchant asked Rob who was going to pay for the plow. Now, Hobbits do not have a formal court system in the same way that we "Big Folk" do. When a Hobbit violates one of "The Rules," as they refer to their laws, which have been handed down since ancient times, it falls upon the master of the house to serve as a combination policeman, judge, and warden. Because Dale and Sam live on Rob's farm The Merchant demanded that Rob insure that he receive nine gold coins for the broken plow.

After listening to The Merchant, Rob decided that his claim was justified and Sam and Dale would have to pay for the plow. One would have to pay five coins and the other would have to pay four, but he was not sure which one should pay more. To make matters worse, "The Rules" prevented Rob from getting personally involved with the settlement. Sam had told Rob that he could only afford to pay four coins for the plow because he needed to pay off the balance of the mortgage on the house he owns in town. He had been saving all year to pay it off. The balance due was one hundred gold coins and Sam only had one hundred and four coins. If he had to pay The Merchant more than four coins he would not have enough left for his mortgage, and since it was due next week he would lose his house. Rob was not sure what to do so he considered his choices.

\section{Directions:}

1. For the first question we want you to describe as many different choices or alternatives that you can think of on the answer sheet.

2. For the second question, pick from the list of choices that you came up with in the first question, which choice you think is the best or the one that you would choose and write it on the answer sheet.

3. For the third question, we want you to list all of the good or positive things and all of the bad or negative things about your choice on the answer sheet.

4. For the fourth question we would like you to describe how you made this choice and write it on the answer sheet.

5. Next, we would like you to take a choice that opposes your Best Choice and write it on the answer sheet.

6. Now, state why this could be a good or better choice on the answer sheet.

7. Finally, considering the other choices available state what you think is the best choice and the reasons why. 


\section{Stealing.}

After they had finished their affairs with The Merchant, the Hobbits had dinner and went to bed. They got up early the next morning and began working. While the Hobbits were working in the field, a friend of Rob's came by with news of his mother. Rob's mother had the same problem with her eyesight that Dale's had. Rob did not have the money for his mother's operation either, and he had far less than Dale. He needed one hundred gold coins. Rob's friend told him that his mother's eyesight was getting worse and that she might go blind. The only one who had that much money was Mr. Maggot, a miserly old scrooge who lived on the next farm. Rob went over to ask him for the money, and Mr. Maggot turned him down. He said that he had worked and saved for a long time and that he wanted to keep his coins. Rob left Maggot's farm, but while he was leaving he saw that Mr. Maggot was going in to town for the afternoon. Rob had seen where Mr. Maggot kept his gold coins and he knew that he could come back in the afternoon and steal the 100 coins. Mr. Maggot had a whole room full of gold coins and would probably never even miss one hundred. Rob knew that there was no other way for him to get that many coins. He wasn't sure about what to do so he considered his choices.

\section{Directions:}

1. For the first question we want you to describe as many different choices or alternatives that you can think of on the answer sheet.

2. For the second question, pick from the list of choices that you came up with in the first question, which choice you think is the best or the one that you would choose and write it on the answer sheet.

3. For the third question, we want you to list all of the good or positive things and all of the bad or negative things about your choice on the answer sheet.

4. For the fourth question we would like you to describe how you made this choice and write it on the answer sheet.

5. Next, we would like you to take a choice that opposes your Best Choice and write it on the answer sheet.

6. Now, state why this could be a good or better choice on the answer sheet.

7. Finally, considering the other choices available state what you think is the best choice and the reasons why. 


\section{Punishment.}

Suppose that before Rob could decide what to do, Sam, who knew about Rob's mother, had already taken the money, and that he had a friend help him. Together, they had taken 200 coins. When Mr. Maggot got back from town he discovered right away that the coins where missing (because it was his peculiar habit to count them three times a day) and went immediately to Rob's farm. At the farm he asked Rob to search the house and they found the 200 coins in Sam's room where he had hidden them. Confronted with the evidence, Sam confessed that he had indeed stolen them. Because Sam and his friend came under Rob's jurisdiction, Mr. Maggot demanded that Rob punish them for stealing the coins, because Hobbits consider stealing a very severe violation of "The Rules." Rob knew the standard punishment for an offense as severe as stealing was to serve time with one's head and hands locked in the pillories in the town square as a form of public humiliation. It was Rob's decision about how much time each Hobbit should spend in the pillories. After confessing, Sam said that he took the coins to give his half to Rob for his mother's operation. Sam's friend, on the other hand, said that he took the coins so that he could use his half to take a vacation trip that he had always wanted. Rob knew that stealing was a very serious offense and he thought about how he might punish Sam and his friend.

\section{Directions:}

1. For the first question we want you to describe as many different choices or alternatives that you can think of on the answer sheet.

2. For the second question, pick from the list of choices that you came up with in the first question, which choice you think is the best or the one that you would choose and write it on the answer sheet.

3. For the third question, we want you to list all of the good or positive things and all of the bad or negative things about your choice on the answer sheet.

4. For the fourth question we would like you to describe how you made this choice and write it on the answer sheet.

5. Next, we would like you to take a choice that opposes your Best Choice and write it on the answer sheet.

6. Now, state why this could be a good or better choice on the answer sheet.

7. Finally, considering the other choices available state what you think is the best choice and the reasons why. 
Directions: Answer the questions on the answer sheet.

Introduction: The following pages tell of the adventures of Rob, Sam and Dale. Rob, Sam and Dale are Hobbits. Hobbits, as you may know, live in Middle-earth. Because some of you may not be familiar with these remarkable people (and those of you who are may be uncertain about many details), we can begin with a few notes about their habits and lives before we start our tale of the adventures of Rob, Sam and Dale. For those of you who find Hobbits interesting and wish to pursue the matter further the best source of information about Hobbits (and the source from which these notes are taken) is J. R. R. Tolkien's The Lord of the Rings.

Hobbits are modest but very ancient people, shy of the "Big Folk," as they call us. They are inclined to be fat and about the same height as Dwarves. Their faces are as a rule good-natured rather than beautiful, broad, bright-eyed, and red cheeked. They are merry and hospitable folk; delight in parties, and in presents, which they give away freely and eagerly accept.

Our knowledge of the history and customs of Hobbits is extensive (and Hobbitlore makes fascinating reading), but these few remarks will serve well enough to set the stage for the adventures of the aforementioned Hobbits--Rob, Sam and Dale. As far as Hobbits go, these three are for the most part representative of their kind. All three are about the same age, though Hobbits tend to live very long and it is hard to tell just exactly what their ages are. The Hobbits' sense of morality is of interest to us because, though it is not widely known, these remarkable people do not differ at all from "Big Folk" in their moral character and conduct. Because it is easy to identify with Hobbits they provide an ideal context for studying how people make choices. The purpose of this questionnaire is to find out how you think about and make choices, and the Hobbits will serve to provide the background for raising these issues. For the next several pages we will be concerned with how Rob, Sam and Dale conduct themselves in various "moral dilemmas." The stories are obviously hypothetical but the situations are intended to represent the type of circumstances people actually frequently find themselves in. Equally obvious, as you will see, there are many different ways to respond to these dilemmas. So try to identify with the situations and answer the questions the way you honestly believe.

Begin by reading the first dilemma. When you are finished reading the first dilemma, answer the questions as indicated.

CPSS.95

Revised: $2 / 96$

Printed: $2 / 98$ 


\section{Lying}

The adventures told here begin on a fine morning, early in the spring. Rob, the more enterprising of the three, had decided to try a hand at farming. Rob had purchased a few acres of farmland not far from where they lived and, because Hobbits are a close knit people, Sam and Dale volunteered to help get the farm started.

As they were walking along the road to the farm, Rob and Sam began talking about Sam's father. Sam had been on a trip to a far away land that took several weeks. While he was away, his father had become seriously ill of an incurable disease and had died. Sam did not find out about his father's death until he returned. Because Hobbits are very close, Rob had spent the last few days taking care of Sam's father. Sam's father had suffered a great deal during his last few days. Rob and Sam were talking about his father, and Sam asked Rob how his father's last days had been and if he had suffered much. Rob thought about what to tell Sam.

\section{Directions:}

1. For the first question we want you to describe as many different choices or alternatives that you can think of on the answer sheet.

2. For the second question, pick from the list of choices that you came up with in the first question, which choice you think is the best or the one that you would choose and write it on the answer sheet.

3. For the third question, we want you to list all of the good or positive things and all of the bad or negative things about your choice on the answer sheet.

4. For the fourth question we would like you to describe how you made this choice and write it on the answer sheet.

5. Next, we would like you to take a choice that opposes your Best Choice and write it on the answer sheet.

6. Now, state why this could be a good or better choice on the answer sheet.

7. Finally, considering the other choices available state what you think is the best choice and the reasons why. 
Rob, Sam and Dale continued on their journey and soon arrived at the farm. The farm was obviously going to need a lot of work. The three Hobbits set to work and the farm quickly began to take shape.

As the day drew to a close, work on the farm stopped. Hobbits, we noted earlier, delight in receiving as well as giving presents and Rob, grateful for the help of Sam and Dale, decided to surprise them each with a nice present. Rob had five gold coins that he wanted to give them as presents for helping. A Hobbit gold coin is quite valuable. The trouble is that Rob could not decide how to share the coins. Both Hobbits had worked all day but Sam had worked harder than Dale. Rob felt he had an obligation to reward Sam more because he had worked harder than Dale. However, Rob also knew that Dale had been saving money for an operation that his mother needed to restore her eyesight, which was failing rapidly. Dale needed only three more gold coins. Rob was not sure about what to do so he considered his choices.

\section{Directions:}

1. For the first question we want you to describe as many different choices or alternatives that you can think of on the answer sheet.

2. For the second question, pick from the list of choices that you came up with in the first question, which choice you think is the best or the one that you would choose and write it on the answer sheet.

3. For the third question, we want you to list all of the good or positive things and all of the bad or negative things about your choice on the answer sheet.

4. For the fourth question we would like you to describe how you made this choice and write it on the answer sheet.

5. Next, we would like you to take a choice that opposes your Best Choice and write it on the answer sheet.

6. Now, state why this could be a good or better choice on the answer sheet.

7. Finally, considering the other choices available state what you think is the best choice and the reasons why. 


\section{Breaking a promise.}

After Rob had given both Sam and Dale their presents, the three Hobbits began to prepare dinner. And it was a splendid supper indeed, for all of the hard work and fresh air had given the Hobbits a healthy appetite. Later, while sitting on the porch, Sam told Rob that he had found a magic black mushroom in the field. Black mushrooms were said to have many different types of powers. For example, it has been said that one bite of a black mushroom could make someone feel very happy. Black mushrooms, however, have also been said to make Hobbits act in strange ways, sometimes even causing them to harm themselves. Now, while Sam had a warm and friendly disposition, he was also noted for being very impulsive and for doing foolish things. Consequently, Sam asked Rob to keep the black mushroom for him. However, before giving Rob the mushroom, Sam made Rob swear a double solemn oath, which Hobbits take very seriously, to give him the black mushroom back whenever he asked for it.

Later on in the evening, in the middle of a fitful sleep, Sam woke up. He had been feeling very bad about his father, and he asked Rob to give him the black mushroom back because he wanted to eat some. Rob was not sure about what to do so he considered his choices.

\section{Directions:}

1. For the first question we want you to describe as many different choices or alternatives that you can think of on the answer sheet.

2. For the second question, pick from the list of choices that you came up with in the first question, which choice you think is the best or the one that you would choose and write it on the answer sheet.

3. For the third question, we want you to list all of the good or positive things and all of the bad or negative things about your choice on the answer sheet.

4. For the fourth question we would like you to describe how you made this choice and write it on the answer sheet.

5. Next, we would like you to take a choice that opposes your Best Choice and write it on the answer sheet.

6. Now, state why this could be a good or better choice on the answer sheet.

7. Finally, considering the other choices available state what you think is the best choice and the reasons why. 
APPENDIX B

THE CPSS ANSWER BOOKLET 
Critical Problem Solving Scale

Answer Sheet

Dilemma I.

(CPSS)

Directions: Use this answer sheet to record your answers.

Describe as many different choices or alternatives that you can think of below.

Question \#1

1)

2)

3)

4)

5)

6)

7)

8)

9)

10) 


\section{Question \#2}

Write what you think is the best choice, below.

Best Choice

\section{Question \#3}

List all of the good or positive things and all of the bad or negative things about your choice, below.

Good

1)

2)

3)

4)

5)

Bad

1)

2)

3)

4)

5) 


\section{Question \#4}

How did you make this

choice?

\section{Question \#5}

Next, take a choice that opposes your Best Choice (above choice) and write it below.

\section{Question \#6}

Now, state why this could be a good or better choice, below.

\section{Question \#7}

Now, considering the other choices available state what you think is the best choice and the reaons why? 


\section{Dilemma II.}

Directions: Use this answer sheet to record your answers.

Describe as many different choices or alternatives that you can think of below.

\section{Question \#1}

1)

2)

3)

4)

5)

6)

7)

8)

9)

10) 
Question \#2

Write what you think is the best choice, below.

Best Choice

Question \#3

List all of the good or positive things and all of the bad or negative things about your choice, below.

Good

1)

2)

3)

4)

5)

Bad

1)

2)

3)

4)

5) 
Question \#4

How did you make this

choice?

Question \#5

Next, take a choice that opposes your Best Choice (above choice) and write it below.

Question \#6

Now, state why this could be a good or better choice, below.

\section{Question \#7}

Now, considering the other choices available state what you think is the best choice and the reaons why? 


\section{Dilemma III.}

Directions: Use this answer sheet to record your answers.

Describe as many different choices or alternatives that you can think of below.

\section{Question \#1}

1)

2)

3)

4)

5)

6)

7)

8)

9)

10) 
Question \#2

Write what you think is the best choice, below.

Best Choice

Question \#3

List all of the good or positive things and all of the bad or negative things about your choice, below.

Good

1)

2)

3)

4)

5)

Bad

1)

2)

3)

4)

5) 
Question \#4

How did you make this

choice?

Question \#5

Next, take a choice that opposes your Best Choice (above choice) and write it below.

Question \#6

Now, state why this could be a good or better choice, below.

Question \#7

Now, considering the other choices available state what you think is the best choice and the reaons why? 


\section{TABLES}




\section{TABLE I}

FACTOR LOADINGS: FORM A

\section{Structure Matrix ${ }^{a}$}

\begin{tabular}{|c|c|c|c|c|}
\hline & \multicolumn{4}{|c|}{ Factor } \\
\hline & 1 & 2 & 3 & 4 \\
\hline CHLDT & .746 & & & \\
\hline CHLD2 & .509 & -.263 & .251 & \\
\hline CHLD3 & .643 & & & -.292 \\
\hline CRED1 & .579 & .284 & & -.258 \\
\hline CRED2 & .692 & & .283 & -.452 \\
\hline CRED3 & .605 & & .347 & -.720 \\
\hline SUSD1 & & .279 & .441 & \\
\hline SUSD2 & & & .968 & -.279 \\
\hline SUSD3 & & & .283 & -.621 \\
\hline MODD1 & & .788 & & \\
\hline MODD2 & & .594 & .255 & -.367 \\
\hline MODD3 & & .593 & & -.412 \\
\hline
\end{tabular}

Extraction Method: Alpha Factoring.

Rotation Method: Oblimin with Kaiser Normalization.

a. Form $=\mathrm{A}$ 
TABLE II

MEANS AND STANDARD DEVIATIONS: FORM A

Mean Std Dev

CRED1

CRED2

CRED3

SUSD1

SUSD2

SUSD3

CHLD1

CHLD2

CHLD3

MODD1

MODD2

4.5072

2.0192

4.4783

1.9600

3.3768

1.4461

1.7536

.5792

1.8116

.4933

1.7246

.6616

$2.0290 \quad 1.2244$

$1.8116 \quad 1.0884$

$1.5507 \quad 1.1053$

.7536

.9611

MODD3

.6522

.8545

$.6667 \quad .8856$ 


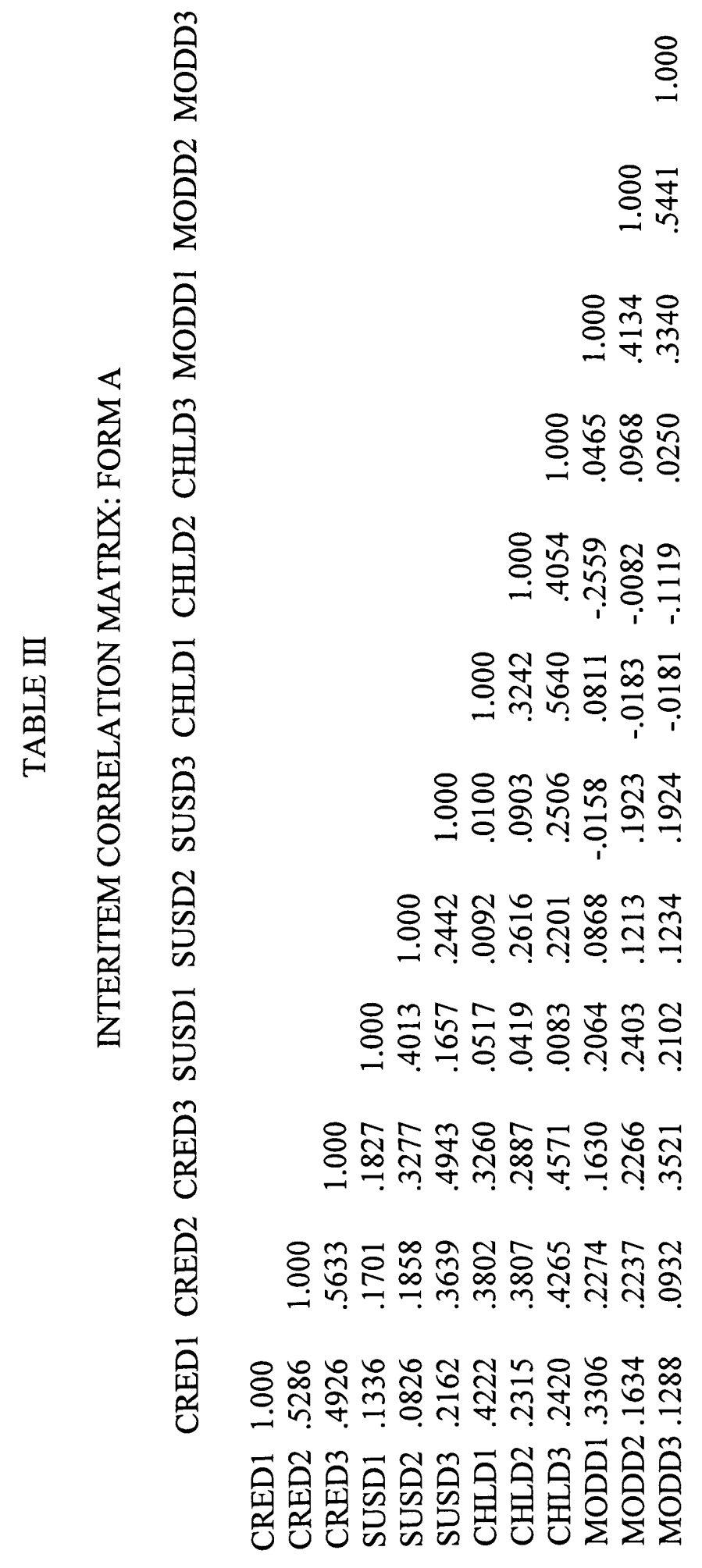


TABLE IV

FACTOR LOADINGS: FORM B

\section{Structure Matrix ${ }^{a}$}

\begin{tabular}{|l|r|r|r|r|}
\hline & \multicolumn{4}{|c|}{ Factor } \\
\cline { 2 - 5 } & 1 & 2 & 3 & \multicolumn{1}{|c|}{. } \\
\hline CHLD1 & .486 & .385 & & -.590 \\
CHLD2 & .350 & & & -.521 \\
CRED3 & .650 & .341 & & -.380 \\
CRED2 & .296 & & .822 & -.603 \\
CRED3 & .413 & .355 & & -.649 \\
SUSD1 & .354 & & & \\
SUSD2 & .414 & & -.434 & -.534 \\
SUSD3 & .800 & & -.486 & -.425 \\
MODD1 & & .692 & & -.391 \\
MODD2 & & .561 & & -.346 \\
MODD3 & & .847 & & \\
\hline
\end{tabular}

Extraction Method: Alpha Factoring.

Rotation Method: Oblimin with Kaiser Normalization.

a. Form $=B$ 


\section{TABLE V}

MEANS AND STANDARD DEVIATIONS: FORM B

Mean Std Dev

$\begin{array}{lrr}\text { CRED1 } & .9420 & 1.7225 \\ \text { CRED2 } & 3.7536 & 1.8818 \\ \text { CRED3 } & 3.0725 & 1.7516 \\ \text { SUSD1 } & 1.8261 & .4838 \\ \text { SUSD2 } & 1.6667 & .7208 \\ \text { SUSD3 } & 1.6087 & .7711 \\ \text { CHLD1 } & 1.6087 & 1.0032 \\ \text { CHLD2 } & 1.4058 & 1.0335 \\ \text { CHLD3 } & 1.4203 & .9912 \\ \text { MODD1 } & .5507 & .8141 \\ \text { MODD2 } & .5797 & .8813 \\ \text { MODD3 } & .4493 & .7772\end{array}$




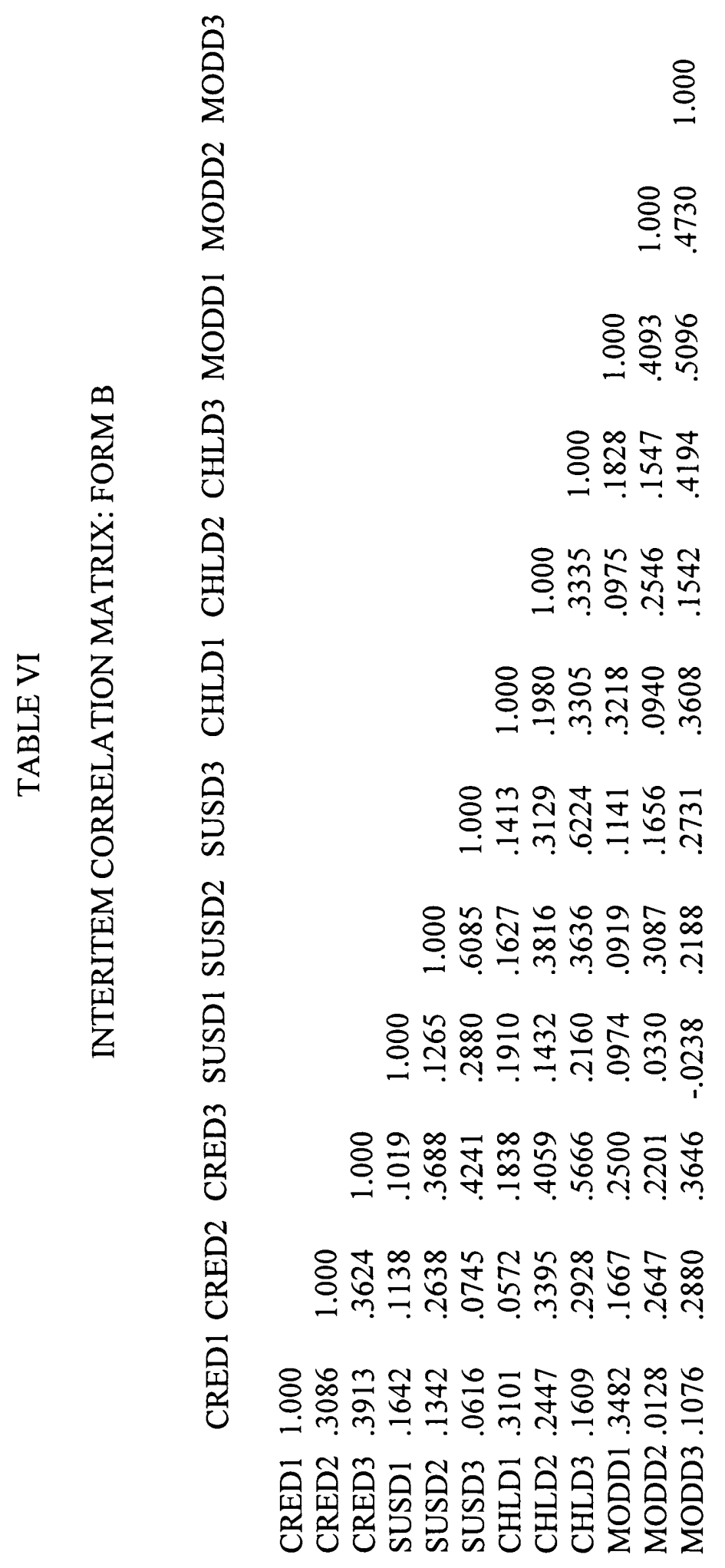


